\title{
8
}

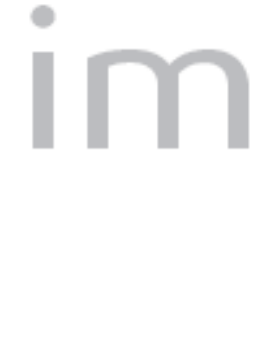

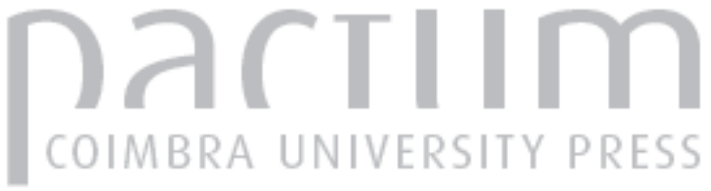

\section{Universos da justiça, no horizonte bíblico}

Autor(es): Ramos, José Augusto M.

Publicado por: Faculdade de Letras de Lisboa, Centro de História

da Universidade de Lisboa

persistente: URI:http://hdl.handle.net/10316.2/23456

DOI: $\quad$ DOI:http://dx.doi.org/10.14195/0871-9527_21_1

Accessed : $\quad$ 26-Apr-2023 15:05:52

A navegação consulta e descarregamento dos títulos inseridos nas Bibliotecas Digitais UC Digitalis, UC Pombalina e UC Impactum, pressupõem a aceitação plena e sem reservas dos Termos e Condições de Uso destas Bibliotecas Digitais, disponíveis em https://digitalis.uc.pt/pt-pt/termos.

Conforme exposto nos referidos Termos e Condições de Uso, o descarregamento de títulos de acesso restrito requer uma licença válida de autorização devendo o utilizador aceder ao(s) documento(s) a partir de um endereço de IP da instituição detentora da supramencionada licença.

Ao utilizador é apenas permitido o descarregamento para uso pessoal, pelo que o emprego do(s) título(s) descarregado(s) para outro fim, designadamente comercial, carece de autorização do respetivo autor ou editor da obra.

Na medida em que todas as obras da UC Digitalis se encontram protegidas pelo Código do Direito de Autor e Direitos Conexos e demais legislação aplicável, toda a cópia, parcial ou total, deste documento, nos casos em que é legalmente admitida, deverá conter ou fazer-se acompanhar por este aviso.

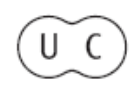



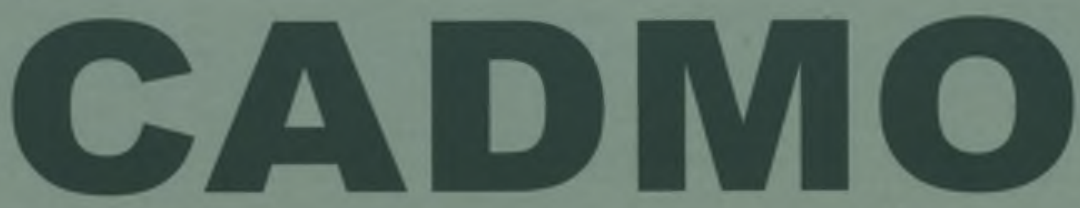

Revista de História Antiga

\author{
Centro de História \\ da Universidade de Lisboa
}

\title{
21
}

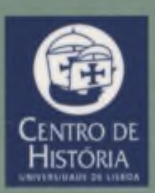

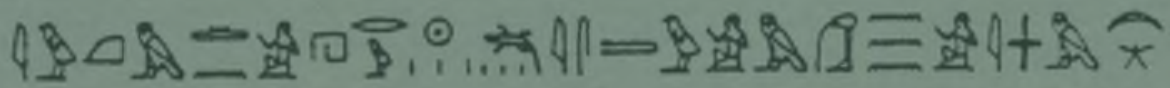

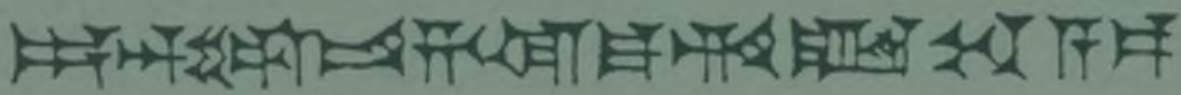

MHNIN AEI $\Delta \mathrm{E} \Theta \mathrm{EA}$ ПH$\Lambda \mathrm{HIA} \triangle \mathrm{E} \Omega$ 


\title{
UNIVERSOS DA JUSTIÇA, NO HORIZONTE BÍBLICO'1
}

\author{
JOSÉ AUGUSTO M. RAMOS \\ Universidade de Lisboa \\ joseramos@fl.ul.pt
}

"Le fait que l'autre, mon prochain, est aussi tiers par rapport à un autre, prochain lui aussi, est la naissance de la pensée, de la conscience et de la justice et de la philosophie.

La responsabilité illimitée, initiale, qui justifie ce souci de justice de soi et de philosophie, peut s'oublier.

Dans cet oubli, la conscience est pur égoïsme."

Emanuel Lévinas é um filósofo. É contemporâneo, mas as suas semânticas exprimem uma profunda sintonia com algumas coordenadas e vectores teóricos, cujas raízes nos levam até ao mundo pré-clássico, tanto na sua vertente semítica como na outra parte, egípcia. Destaca-se particularmente o facto de que a consciência de se ser humano assenta no reconhecimento da solidariedade pela qual nos descobrimos inseridos numa rede social. Estes dados justificam a opção de colocarmos um texto deste filósofo, marcado pela tradição de pensamento judaico, como epígrafe das considerações que aqui propomos sobre os universos da justiça, na amplitude cultural dos horizontes bíblicos.

Diz então Lévinas que "o facto de o outro, meu próximo, ser igualmente terceiro relativamente a mais um outro, que é próximo ele também, assinala o nascimento do pensamento, da consciência e da justiça e da filosofia. A responsabilidade ilimitada, originária, que justifica este cuidado pela justiça, por si e pela filosofia, pode ser esquecida. Neste esquecimento, a consciência é puro egoísmo." Esta sentença filosófico-talmúdica de 
Lévinas $^{2}$ é uma epígrafe inteiramente pertinente para este texto e poderia servir igualmente como epílogo e ponto de chegada deste tema.

Através de variados exemplos de composição semântica entre filosofia e judaísmo, este filósofo de origem judaica coloca-se numa rota de convergência entre filosofia e tradições semânticas do mundo oriental antigo, tal como, há tempos, nos pareceu ser igualmente aplicável ao pensamento do $P$. Manuel Antunes. Também o pensamento deste último se nos desenha em linha de convergência entre o classicismo, assumido como o seu e nosso modo de pensar em processamento racional e filosófico, e vários outros discursos de raiz oriental, de modo particular aquele que tradicionalmente se cultiva como teologia. Segundo a prática de pensar de Manuel Antunes, estes últimos modelos de discurso são portadores de conteúdos semânticos, que se tornam necessários, imprescindíveis mesmo ao tratamento humanístico de numerosas questões do nosso tempo ${ }^{3}$. Esta chave de entrada sugere que o alcance deste tema nos poderá conduzir para domínios profundos e decisivos do mundo cultural que serve de horizonte ao homem dos tempos bíblicos.

\section{No cerne da questão: estrutura, sistema e sentido}

No horizonte cultural do mundo pré-clássico, que, ao encerrar o seu ciclo histórico, deixou uma imagem essencial de si mesmo espelhada na Bíblia $^{4}$, o conceito de justiça transcende claramente o âmbito simples e imediato da equidade distributiva em matéria de direitos e deveres dos indivíduos na sociedade. A justiça representa um âmbito de fundamentação universal, no qual cada realidade e cada acção adquirem significado e lógica e garantem motivos de interesse e satisfação. É com base no conceito de justiça que se define a essência reconhecida e aceite, relativamente a cada ser e a cada acto, bem como a cada função ou agente ${ }^{5}$.

$\mathrm{Na}$ verdade, a justiça é também a justeza. Ela representa a ordem e o sentido essencial de todas as coisas bem como define o estado do mundo num determinado momento. Com efeito, o estado do mundo é sempre comparado com o padrão ideal que lhe serve de fórmula essencial e que, em momentos de insatisfação, se the sobrepõe como recurso compensatório e correctivo ou como solução libertadora.

Sendo esta a base em que assenta o sentido esperado do mundo e das coisas, este conceito de justiça significa ordem, prestabilidade e funcionalidade. Como sistema completo de fundamentação da realidade, ela acaba por definir uma visão positiva e optimista sobre o universo. Isto 
quer dizer que o mundo em que os humanos vivem e a vida que nele assumem são realidades importantes, têm lógica e merecem confiança. Quer isto dizer que essas vivências têm sentido e utilidade e tendem para metas que parecem garantir satisfação. A intencionalidade definida pelos desejos humanos tem aqui a sua fundamentação e, por consequência, também a sua realização.

Este horizonte de optimismo revela-se como um sistema de ampla e fina textura e coincide, no essencial, com alguns conceitos directores das culturas da Antiguidade oriental. Cada uma das várias culturas ali construiu um sistema próprio de referências e de valores para exprimir esta coesão, mas é possível detectar o horizonte sistémico que lhes permite interagirem entre si.

O caso do Egipto talvez seja o mais imediatamente equivalente. O conceito de ma'at transmite-nos de imediato a ideia de uma ordem geral e universal, se bem que possa igualmente representar a justeza e correcção de cada atitude e de cada passo do comportamento humano. Ma'at define, portanto, a integridade de cada acto humano e a sua adequação com as normas e valores de comportamento. Uma vez que se trata de uma entidade abstracta de género feminino, ela define igualmente o estado geral e o sentido que sustenta o mundo e que nele realmente transparece. Este sentido ou esta ordem podem também apresentar-se em estado de carência. Por isso, cuidar da justiça, que é harmonia e verdade, constitui uma norma, uma tarefa e uma obrigação moral permanente. As incumbências neste capítulo definem a transcendência das funções que cada um assume na sociedade; e os resultados desta actuação aparecem sempre repercutidos no estado em que se encontra o universo e no mérito com que se define o valor dos seres humanos ${ }^{6}$.

A história desta ideia na cultura egípcia pode até servir-nos para aferir algo de muito importante na análise estrutural deste conceito de ordem, que nem sempre se consegue descortinar e decifrar inteiramente. É, concretamente, a questão de saber onde é que poderiamos detectar o embrião originário deste sentimento que engloba justiça, ordem e harmonia. A ampla ressonância que teve no Egipto poderia fazer-nos pensar que o sentido global e sistémico, por ser o que apresenta maior ressonância e por se traduzir em contemplação imediata e englobante de tudo, seria aquele que marca a sua fonte e ponto de partida. A sua origem encontrar-se-ia numa intuição sistémica: a apreensão global da ordem como estado adequado e desejado do universo.

No entanto, Jan Assmann ensaiou uma análise em profundidade sobre o percurso evolutivo deste conceito $^{7}$ e parece ter chegado à conclusão 
de que a génese da ideia de ordem e justiça se deveria encontrar mais directamente na intuição social imediata e primária do próprio agir humano e da estrutura de relação interpessoal implícita nesta coexistência consciente e assumida. A projecção universal deste sentido de cumplicidade ética seria uma transposição feita a partir da experiência e da intuição imediata da partilha de sentidos e interesses entre os humanos; aqui se encontra a base e a matriz originária da existência em sociedade. Um tal núcleo envolve, como estrutura, o individual e o social e projecta-se em sistema para horizontes cósmicos, quase como um silogismo cartesiano. É um sentimento miticamente projectivo. E só alguns tempos mais tarde é que esta intuição parece cruzar-se de maneira explícita com a moral e a ética humanas, de modo a funcionar como critério moral e como garantia específica para os caminhos desejados da imortalidade ${ }^{8}$. A concepção da justiça no Egipto seria essencialmente antropológica.

O mundo da Mesopotâmia parece ter diversificado um pouco mais a nomenclatura sobre estas questões. É claro que com frequência sobressai na literatura suméria a palavra me, praticamente intraduzível, como sendo um conceito que se movimenta por entre alguns destes significados. Percebem-se claramente as conotações de transcendência presentes nas realidades catalogadas pelos sumérios como me. No entanto, algumas das listas que nos são apresentadas podem causar-nos perplexidade quanto à definição de um tal conceito ${ }^{9}$. Algumas das realidades e conceitos com ele identificados, como a realeza sagrada, não nos levantam dúvidas; outros casos, porém, como o de uma espécie de enxada, por exemplo, poderiam suscitar-nos mais interrogações. Fica-nos, de qualquer modo, a sensação de que o núcleo deste conceito sumério tinha já bastante a ver com funcionalidades previsíveis e pertinentes dos conceitos, das instituições e dos objectos bem como de outras realidades humanas, sociais e cósmicas.

Entretanto, a convergência deste conceito com alguns outros, como os de destinos ou de funções, ajuda-nos a compor um universo de ordem e de sentido, um mundo vário e complementar, que traduz a mesma concepção. É também o que se verifica com a evolução para os conceitos em vigor nas épocas seguintes. Com efeito, as ressonâncias sistémicas do termo sumério me foram em geral representadas na literatura semítica da Mesopotâmia pela tradução de um outro termo sumério, namtar. Este significava já alguém que detém a prerrogativa de impor os destinos.

Numa função equivalente a esta, está o substantivo acádico de género feminino, šimtu, derivado de um verbo que, por todo o semítico comum, significa colocar. Ele indica, por conseguinte, uma imposição ou 
incumbência, uma função: é esse o sentido da palavra destino. Por isso Ihe fica tão bem o plural. Esta última acepção é a mais séria candidata a representar o conceito de sentido, de ordem e de justiça. A falha no cumprimento de um ditame de ordem e sentido para o mundo tem sempre algo de desobediência. Com efeito, realizar essa ordem é uma função que se nos impõe e da qual estamos incumbidos. É nesse sentido que os mesopotâmicos acreditam no destino ${ }^{10}$ : não como uma servidão, mas como uma filosofia.

Neste sentido e segundo a sua perspectiva, o conceito de justiça apresenta uma conotação marcadamente heteronómica, no sentido em que coincide com a função que foi destinada a cada coisa. Essa é, por conseguinte, a sua definição funcional, o seu papel e tarefa no sistema total do mundo. Essa função é recebida da parte de quem tem autoridade para tal. E é por isso que a literatura semítica da Mesopotâmia fala mais em decretar os destinos do que propriamente em justiça. Os conceitos abstractos de "honestidade" e "justiça" são também expressos como kittum e mišarum, de raízes igualmente utilizadas na Bíblia; estes são importantes para exprimir a justiça como correcção do agir. Assim aparecem valorizadas na linguagem do código de Hamurabi ${ }^{11}$.

Esta consciência de uma autoridade que decreta destinos e assim programa funções, definindo o sentido e a justiça, não é uma certeza ingénua sobre a existência de um deus programador, é uma leitura estrutural e funcional do humano e do mundo. A heteronomia consiste em aperceber-se de que a lógica do conjunto é maior do que a consciência do agente singular.

$\mathrm{Na}$ literatura bíblica, o conceito de justiça deriva do léxico e campo semântico da raiz şadaq. Esta é uma raiz muito característica do semítico ocidental do Norte. E a Bíblia oferece, para este conceito e termo, o conjunto literário com maior complexidade no contexto pré-clássico. Esta não é uma frase de conveniência, por se tratar de Bíblia. Na verdade, este tema é, ali, de uma riqueza tal que não cabe evidentemente nesta abordagem. É já interessante o facto de K. Koch destacar, em título, que o essencial do conceito de justiça é o de ser fiel para com a sociedade ou ser útil e salutar ${ }^{12}$. Estamos no horizonte caracterizado pela ideia de funcionalidade. Isto significa que, mais do que tratar dos aspectos mais individuais ou comportamentais da justiça, é o seu papel de sustentação da vida em sociedade, aquilo que avulta especialmente. Por isso, esta justiça apresenta tantas conotações com a função de governo exercida pelos reis e se presta de uma maneira tão natural a servir de metáfora para formar nomes de divindade ${ }^{13}$. 
No mesmo artigo, Koch introduz um número específico para tratar comparativamente o caso da ma'at egípcia ${ }^{14}$. O interesse está certamente nas analogias semânticas, porque filologicamente não parece que exista nenhum parentesco entre ambos os vocábulos. Também esta representa um conceito abstracto e igualmente uma divindade. A história das divindades semíticas do noroeste não recorda nenhuma divindade com o nome de Sédeq. Em nomes teofóricos, no entanto, este termo pode representar um predicativo semanticamente importante. É o caso de Adoni-sédeq, «o meu senhor é Justiça». Com este predicativo divino estava, pelo menos, a afirmar-se ou a sugerir-se uma certa hipostatização da justiça como uma entidade divina, tal como, no livro dos Provérbios, vemos acontecer com o conceito homólogo de hokmah, que significa a "sabedoria»" ${ }^{15}$. Uma tal hipostatização de şedeq, que seria análoga à que ocorreu no Egipto com ma'at, não ocorreu claramente na Bíblia. Mesmo que o verbo desta raiz seja razoavelmente utilizado no hebraico, o conceito aparece sobretudo, e por esta ordem, referindo o homem justo (şadiq), a justiça em abstracto (şedeq) e as acções concretas de justiça (şedaqah) ${ }^{16}$.

Na tradução da Bíblia para o grego, em Alexandria, os termos dikaios (justo) e dikaiosyne (justiça) ${ }^{17}$ mantiveram os referidos conteúdos mais ou menos no mesmo âmbito e transportaram a questão para a linguagem grega e para o pensamento que o Novo Testamento foi definindo, servindo-se da língua helénica.

São múltiplos, por conseguinte, os universos que o conceito de justiça convoca para o nosso entendimento, no contexto cultural do mundo bíblico. A justiça é aquilo que é devido, direito e correcto. Por outras palavras, é também aquilo que é necessário, previsível, legítimo e legal. E poderíamos seguramente acrescentar a esta lista mais outros matizes igualmente importantes. É uma amplitude semântica rica e variada.

Um desejo, uma expectativa ou uma ponderação ainda mais ampla podem ser os critérios para aferir o grau tão maleável de satisfação provocado pelo estado do mundo. Joga-se aqui um processo de balanço e definição, ambos naturalmente complexos. Justo, certo e bom são conceitos dotados de alguma equivalência, mas têm matizes diferentes e fronteiras que podem nem sempre coincidir. Podem, desta maneira, gerar insatisfação e discordância. Essas são as margens maleáveis da busca da justiça. Na vertigem dessa procura, é possível definir graus de satisfação e garantias de realização. A justiça abrange desde o nível mais estrito dos deveres até à atitude mais exigente, generosa e à dimensão mais abrangente e utópica. 
Já dissemos que uma das principais características da formulação do sentido do mundo e das coisas, segundo os critérios do antigo Oriente pré-clássico, consiste em explicitar para que é que serve cada coisa no concerto do universo. É a esta proclamação que eles chamam «decretar o destino". Esta solenidade, de inquestionável marca litúrgica, é expressiva do conteúdo. É num mito que se costuma designar como «Enki e a ordem no mundo" que aparece introduzido por um duplo coro litúrgico de deuses, os Anunaki e os Igiggi, que aquele deus sumério, grande definidor de tarefas e sentidos, decreta os destinos de divindades, de cidades e de países ${ }^{18}$, bem como de outras entidades responsáveis por tarefas importantes no mundo.

Formular a intencionalidade e a prestabilidade de tudo aquilo que existe com a declaração da sua função é colocar a tónica do sentido numa dimensão concreta, produtiva e útil. Por isso mesmo, esta maneira de ver se torna bastante perceptível e saudável. Talvez isto possa equivaler àquilo que hoje chamaríamos fazer uma boa gestão das expectativas. Também por aqui se vai insinuando um saudável realismo e se joga alguma lucidez.

\section{A imputabilidade da justiça}

As expectativas que alimentamos relativamente aos vários domínios do mundo e da vida facilmente aparecem formuladas no nosso espírito como se fossem direitos insofismáveis que temos, naturalmente instalados como eles se apresentam no nosso sistema de realidade. Assim claramente definidos como direitos nossos, eles são de imediato e automaticamente transformados num dever que tem de ser imputado aos outros, da forma mais taxativa e abrangente possivel. É esta a dinâmica implicada nos conceitos correlativos de direitos e deveres; é a nossa relação com o mundo enquanto apetite e exigência. Parece absolutamente lógico; exijo aquilo a que tenho direito. $\mathrm{E}$ a vontade subjectiva com que se assume este alcance do conceito de justiça apresta-se a traduzir essa mesma exigência, com toda a naturalidade. Quando os agentes são humanos, é a eles que se tende a exigir o cumprimento desta amplíssima vontade de justiça, de modo mais ou menos taxativo.

Pelo contrário, quando se trata de coisas que dependem da "acção" da natureza, do universo ou, ainda mais genericamente, da vida, torna-se mais difuso e indefinivel saber a quem atribuir essa responsabilidade. Nesse caso, o homem pré-clássico acha mais lógico que tais acontecimentos 
sejam ainda imputáveis a uma entidade, considerada suprema no poder e também na responsabilização e na eficácia. O mais habitual é, então, que esta imputabilidade seja endossada a um deus ou à assembleia dos deuses, em última instância. Isto significa que o conceito de Deus assenta sobre uma visão lógica do mundo. De forma inesperada, podemos andar por perto do argumento ontológico de Santo Anselmo.

Esta é mais uma maneira de sublinhar a ideia de confiança que se tem no funcionamento do universo. O facto de, aos vários níveis, haver sempre maneira de atribuir a alguém a responsabilidade pelo funcionamento das coisas parecia ao homem pré-clássico que seria uma perspectiva positiva e lógica de olhar o mundo. Está pressuposto que esse alguém assim postulado é capaz de cumprir. Por isso, a concepção de Deus resulta natural e eficaz para os homens do antigo Oriente, precisamente, porque faz sentido. Não é por assentar em provas de verificação sobre a sua existência. Este aspecto não os preocupa. A certeza fundamenta-se na intuição global do seu significado como maneira de garantir sentido e funcionalidade para o universo. Deus é, para eles, a última metáfora de ser, na sua totalidade e viabilidade apreendidas.

Imputar responsabilidades sobre os grandes acontecimentos da vida e do universo poderia ser feito com a intenção de exigir expectativas como se fossem direitos. Esta atitude sugere ao interessado que o seu descontentamento pressupõe algo de injusto. Entretanto, imputar responsabilidades a uma entidade absoluta é uma forma épica e mítica que serve para responsabilizar e exigir mas também para celebrar e para louvar. As tonalidades matizadas da experiência fazem a divisória entre essas duas intencionalidades.

$\mathrm{O}$ aspecto positivo desta imputabilidade absoluta é aquele que aparece mais frequentemente sublinhado na Bíblia. A fisionomia de Deus não segue normalmente o modelo jobiano, marcado pelo queixume e pelo protesto, por muito legitimamente humanos que esses sentimentos ali se apresentem. Aliás, a adoração, sendo como é a maneira mais normal de exprimir a consciência religiosa é igualmente o sentimento que melhor traduz o estado de satisfação face à vida e ao mundo. Para os aspectos de ingenuidade que poderiam aninhar-se nestes meandros, não faltam experiências de fronteira que provocam dramáticas tomadas de consciência.

O homem pré-clássico sente-se incomodado face ao imprevisível. O domínio do imprevisível é ingovernável; e o homem médio-oriental não se resigna a viver num mundo que não garanta o máximo de previsibilidade, para conseguir a maior eficácia no governo das coisas. Precaver-se 
contra o imprevisível é uma atitude de responsabilidade e eficácia e isso oferece garantias. Pelo contrário, não ter a possibilidade de imputar responsabilidade sobre a justiça ou a injustiça de tudo aquilo que pode ocorrer no mundo é uma terrivel fonte de insegurança. E esta insegurança provoca uma profunda ressonância na mente humana.

Há uma outra dimensão que se pode inscrever neste horizonte da imputabilidade de tudo aquilo que existe e vai acontecendo. É o conforto e o encanto que se descobre ao sentir que se vai recebendo o mundo e a vida das mãos de alguém, como uma dádiva de cumplicidade interpessoal, generosa e reconfortante. A consciência pessoal personaliza de algum modo a relação com tudo o que nos circunda. A expressividade poética traduz isso com eficácia, quando deparamos com os estados de excesso vivencial a transbordar em conversa intensa com um universo subitamente personificado.

\section{Aporias da imputabilidade: o absurdo e o mal como injustiça}

O absurdo é sem dúvida um mal para os humanos, uma vez que só um mundo lógico lhes parece aceitável. É o mundo que eles desejam e merecem e ao qual sentem ter direito. Por isso se questionam e se incomodam tão profundamente, quando se confrontam com dados e situações absurdas. O absurdo, o monstruoso e o prejudicial são dimensões consideradas injustas na vida e na história como na natureza.

Com aquela necessidade de articular todas as ocorrências num sistema universal de imputabilidade, estas realidades anormais tornavam muito difícil atribuir capacidade e responsabilidade sobre acontecimentos que pareciam completamente inaceitáveis. Os deuses pré-clássicos são principalmente sujeitos de imputabilidade positiva. Atribuir-lhes um mal de forma radical sempre foi um passo desconfortável.

Esta difícil questão foi belamente tratada num mito sumério intrigante e bastante sugestivo ${ }^{19}$. O problema concreto decorre do nascimento de seres humanos com grave deformações. A explicação está em admitir que isso se deva a um atrevimento de criação por parte de uma divindade menos habilitada que acolheu de forma pouco ponderada o desafio de criar. Esta atitude representa uma brecha no tema da imputabilidade positiva referida aos deuses criadores. Segundo a lógica de expectativa que seria normal normal, tais criaturas deveriam ser seres humanos escorreitos. Porém, eles foram aparecendo com variadas anomalias graves: quatro homens que tinham malformações físicas, uma mulher 
que se revelou ser estéril e uma espécie de ser humano que nasceu sem ter o sexo definido.

O mito procura fazer uma leitura lógica, justa e eficaz dessas realidades incomodamente ilógicas e por isso injustas. Em primeiro lugar, a monstruosidade é do domínio da criação; ela é, portanto, imputada aos deuses criadores. Mas como? Foi como que um desafio entre duas divindades, para um jogo de criação. A menos habilitada entregou-se com entusiasmo àquele desafio, mas foi sofrendo sucessivas falhas, a cada novo protótipo que ensaiava.

Entretanto, a divindade maior, para a qual esta espécie de «brincadeira" poderia ser uma condescendência, mas não era de todo uma irresponsabilidade, foi arranjando sempre um sentido e uma ocupação para cada um daqueles aleijadinhos, destinando-Ihes funções adequadas na sociedade humana. Também eles viam garantida uma "colocação", um destino; a sua vida ganhava novo sentido, tornava-se lógica e, apesar de tudo, satisfatoriamente justa e até compensadora, tendo em conta a deficiência de onde partiam. Esta era uma maneira engenhosa de recuperar e integrar as monstruosidades dentro do sistema, sem pôr em causa a tese da imputabilidade de tudo aquilo que acontece no universo.

O livro de Job trata de uma irregularidade fundamental no sistema do agir humano, apontando o caso pessoal de Job que parece constituir uma injustiça absoluta e inaceitável. Job é completamente inocente. Não tem culpas que justifiquem todas as desgraças que lhe aconteceram na vida ${ }^{20}$. Contrariamente à opinião daqueles que são declarados seus amigos, Job insiste em que a culpa deveria ser atribuída a Deus, que é o único sujeito ao qual se poderia imputar a responsabilidade pelas desgraças que o afligem. Por isso, os estudiosos acham que o género literário em que se desenvolve o livro de Job é o modelo que corresponde ao de uma acusação forense ${ }^{21}$, género literário que exprime a citação de alguém para responder em tribunal.

No final do livro, a solução mais criativa e menos aporética que foi encontrada consistiu em projectar o problema para uma imensa zona de mistérios maravilhosos da natureza. Desta maneira se procura diluir e relativizar o peso da pergunta irrespondivel. Este é o epílogo da parte poética e a solução que apresenta consiste na intervenção única e final de Deus, seguida de imediato por uma resposta, já serena ou resignada da parte de Job, ele que aparecera inicialmente tão chocado com o escândalo da injustiça ${ }^{22}$.

Pelo teor de uma segunda conclusão final do livro, já de novo em prosa, ficamos a perceber, no entanto, que, para alguns, este horizonte de 
solução parecia ainda pouco convincente: seria poeticamente sugestivo, mas renunciava à lógica. Para esses, pareceria mais válido e mais evidente dar um final diferente à história de Job com a recuperação de tudo aquilo que ele tinha perdido: recuperou a saúde, os bens e até mesmo os filhos mortos. É o epílogo em prosa ${ }^{23}$. E será eventualmente de um gosto mais popular, sem capacidade para aceitar uma lógica que deixasse aberta a possibilidade de falhas ou mistérios.

Esta tragédia existencial de Job tinha uma longa história de vivências e são conhecidos antepassados literários importantes. O tema das incomodidades antropológicas com sabor a injustiça metafísica é objecto de criação literária desde o tempo dos sumérios ${ }^{24}$. Esta tradição de reflexão tem um dos seus lugares clássicos no poema acádico designado Ludlul bel nemeqi. O verso inicial que Ihe serve de título, tal como é convencional fazer-se para a literatura poética ${ }^{25}$, exprime a intenção de dar ao poema a modalidade de uma reflexão profunda ${ }^{26}$.

É costume considerar este texto como um dos que tratam dos problemas da teodiceia na Babilónia. Na verdade, este rótulo define-o como um tratado sobre a justiça divina; e isso traduz bem a concepção pré-clássica de que estas questões fundamentais da justiça nas margens profundas e misteriosas da antropologia se constituem naturalmente como questões pertinentes de teodiceia. Pertencem, portanto, à maneira como se concebe e define o papel de Deus, enquanto última possibilidade de se imputar responsabilidade, a partir das interrogações humanas sobre o funcionamento justo da sua criação.

Os deuses, como último nível da cadeia de agentes imputáveis por tudo aquilo que acontece no universo e particularmente no universo humano, mantêm, desta maneira, um significativo capital de confiança da parte dos humanos. Tal confiança resiste, mesmo quando estes últimos tropeçam em acontecimentos que Ihes deixam um sabor claro a «injustiça» e não conseguem formular respostas capazes de neutralizar completamente a dúvida e a incomodidade.

O mito sobre o nascimento de seres humanos com qualquer deformação bem como as tragédias de consciência tratadas no livro de Job e nos seus equivalentes mesopotâmicos são um exemplo de como a perplexidade pode ser levada até a um ponto de grande tensão, pondo em causa a visão satisfeita e confiante com que o homem do antigo Oriente gostava de assumir a sua situação, na sua vida individual e em sociedade, bem como na sua projecção mítica para o horizonte do universo. E tudo isto, sem quebrar de maneira irremediável a confiança na consistência e na «justeza» do sistema em que se enquadra e desenvolve a vida 
dos humanos. Impunha-se que prevalecesse a intuição fundamental da consistência, sinal de uma atitude sadia relativamente ao posicionamento dos humanos na vida e à sua integração no universo.

$\mathrm{O}$ aparecimento de sistemas que recorrem à imputação dualista relativamente ao mal e ao bem que acontecem deixa entender que a alternativa de imputar tanto o mal como o bem a uma mesma entidade divina dava a impressão de conter aspectos excessivos e inaceitáveis, no tocante a esta imputabilidade absoluta. O caso mais conhecido a favor desta dupla imputabilidade, na época antiga, deve ser o do zoroastrismo, definido ainda em tempo pré-clássico, mas num espaço cultural um pouco marginal ao núcleo principal do mundo oriental antigo, mas que acabou por se enquadrar e articular de maneira bastante natural com várias das culturas de raiz pré-clássica ${ }^{27}$. Este recurso a uma dupla imputabilidade deixa, no entanto, algum sabor a simplificação. Parece claramente excessivo.

\section{A justiça do homem}

Começámos este percurso relativamente aos agentes da justiça, tentando intuir, por dentro das vivências humanas, as fontes conceptuais da mesma, pois as dimensões interpessoais do agir constituem a base vivencial, onde a ideia de justiça se define e se estrutura e onde ganha as suas conotações mais pertinentes. É desta base que a noção de justiça se expande e se esboçam as suas projecções metafóricas. À semelhança daquilo que assinala Jan Assmann e que atrás referimos para o caso egípcio de ma'at, é deste nível que ganham forma os outros dois níveis a seguir considerados, apesar de, em cada um dos seguintes, nomeadamente o da justiça do rei e o da justiça de Deus, se poder assistir a um progressivo acentuar dos aspectos de transcendência. Todas as implicações de justiça e de ordem que podemos detectar no âmbito social e cósmico provêm efectivamente da riqueza de conotações, significado, medida e imputabilidade que para ela podemos definir, ao nível da partilha humana. Esta é a matriz da intuição originária de solidariedade e justiça. A epígrafe de Lévinas à cabeça deste texto foca esse horizonte precisamente.

E esta perspectiva mantém-se, mesmo que o equilibrio de alguns dos matizes, como o da imputabilidade, se tenha mostrado frequentemente, ao longo da história, difícil de formular. Com efeito, a leitura que fazemos do mundo implica sempre algo de dialogante relativamente a um tu, que 
não se define como equiparado ao nosso próprio nível e, por isso, se nos apresenta como transcendente.

Não gostaríamos de, com estas reflexões, estar a apadrinhar a terrível tentação fundamental dos humanos, tendente a extorquir do outro aquilo que se sentem no direito de exigir da vida. Tal exigência excede claramente as capacidades de prestação de qualquer ser humano. É, portanto, injusto pedir satisfações a quem quer que seja sobre algumas das injustiças que a vida nos provoca. $\mathrm{E}$, no entanto, essa tentação ocorre da forma mais espontânea, recusando-se a desistir. Provavelmente será porque as razões estruturais persistem. E por muito desagradável que este comportamento nos pareça, ele assenta nas mesmas razões que, de início, apontávamos como matrizes do próprio sentido de justiça, nos seus aspectos benéficos. Esta lógica de postulado deve integrar igualmente a génese do conceito de Deus.

$\mathrm{Na}$ verdade, os matizes do conceito bíblico de justiça, que vê o agir humano como um sistema de múltiplas implicações, concordam bem com este horizonte. A prática da justiça entre os humanos implica evidentemente o cumprimento daquilo que é taxativamente devido, por obrigação, por contrato, por lei ou por promessa. Por estes comportamentos se pode aferir formal e oficialmente se alguém é justo ou não é justo. Recorre-se, por isso, ao juiz como instância destinada a declarar a situação de cada humano face à justiça; e a sociedade tem no processo de apuramento que culmina com a sentença do juiz um dos seus pilares mais significativos de sempre. Isto vem a significar que o destino essencial do humano se joga na relação justa que estabelece com o outro. Voltamos a encontrar por aqui a fonte levinasiana da consciência como solidariedade.

É verdade que esta apetência normativa para definir o justo agir dos humanos parece uma característica bíblica muito marcante. De tal maneira isto assim é que a parte principal da Bíblia passou a ser chamada a Lei. E, se assim aconteceu, é certamente porque a perspectiva tem alguma pertinência.

No entanto, a ideia de fazer coincidir o essencial da Bíblia com a intenção de normatividade não é uma leitura absolutamente pertinente. A descoincidência desta interpretação com o próprio conceito hebraico de torá é absolutamente evidente. O salto hermenêutico que foi feito com a assunção do termo grego nómos como equivalente de torá também não ajudou muito. A imagem negativa de uma justiça segundo a Lei, tal como ela decorre dos combates de Paulo por novos horizontes do agir 
humano, acrescentou ainda alguns outros mal entendidos. O conflito tem tendência a promover aspectos de alguma caricatura.

Nas linhas dialécticas da hermenêutica de Paulo, há mesmo alguma contraposição entre a lei e a nova «justiça» ${ }^{28}$. O certo é que o conceito de justiça, ao longo da Bíblia, como critério satisfatório para o agir humano, ultrapassa muito claramente os limites da simples justiça distributiva e retributiva. Segundo estes, para se ser justo, bastaria cumprir aquilo que se encontra estipulado como estritamente obrigatório.

Ora, o que é por norma taxativo são os objectivos mínimos; é desse limite que trata normalmente o tribunal. O conceito de justiça, no entanto, desenvolve-se e cresce daí para diante até atingir um horizonte de prestação sem limite predeterminado, mas que se vai definindo, de forma aberta e crescente, tomando como verdadeiro padrão a ponderação da necessidade, por parte de quem recebe, e da generosidade, por parte de quem empresta. $\mathrm{O}$ excesso é, pois, a medida pertinente desta justiça. Quebrar os grilhões injustos de todos os prisioneiros e partilhar o pão com todos os esfomeados, dar guarida aos sem abrigo e roupa aos que andam nus à intempérie também são actos de pura justiça ${ }^{29}$. No entanto, não seriam medidas exigíveis em tribunal. Ser generoso para com os pobres é praticar um tipo de justiça que oferece todas garantias ${ }^{30}$. Ela é autêntica e duradoira.

Com efeito, tanto na expressão do original hebraico (şedaqah) como na transposição para o grego de uso corrente entre os judeus da diáspora (dikaiosyne), fazer justiça significa também dar esmola; e, muitas vezes, é sobretudo isso. Sem sair do vocabulário da justiça, as recomendações e os exemplos de comportamento apresentados integram no campo da justiça toda a amplidão de sentidos da caridade ${ }^{31}$. Quando Jesus fala de uma atitude de justiça que é superior àquela que praticam os escribas e fariseus ${ }^{32}$, é para sublinhar com toda a intensidade que é importante assumir uma prática da justiça que esteja situada no horizonte da generosidade e não dentro dos limites taxativos da imposição legal. Esta última era o padrão com que o discurso farisaico parecia estar obsessivamente preocupado.

Este nível da justiça poderá conter dimensões e matizes que não são evidentemente para discutir diante do juiz. No entanto, esta dimensão da justiça é altamente valorizada na avaliação essencial do humano. Com efeito, ela abarca o ponto de vista ético, valoriza outros sentidos antropológicos e cumpre a função de garantir vida aos que precisam. Ora esta função não sofre desilusão.

A pertinência deste excesso de dom pode eventualmente suscitar algumas dúvidas ou desilusões quanto à recompensa que haveria de 
corresponder por isso a quem a pratica. Se a prática de uma justiça a extravasar da sua medida legal tem sentido e é benéfica para os outros, também para os que a praticam o deveria logicamente ser.

O homem bíblico, que não elabora teorias de recompensa projectadas para além da morte, considera que o agir ético contém em si mesmo a sua própria sanção. Só que, por vezes, as contas entre o dar e o receber parecem sair claramente erradas e injustamente desproporcionadas. Esquece-se que a justiça implica alguma obrigação de se ser excessivo no dom; e cede-se à tentação de pedir contas por aquilo que se deu. O livro de Job é um tratado literariamente brilhante sobre esta aporia. E se o dramatismo da questão parece ter sido mais ou menos resolvido no final do livro, ele parece conservar toda a sua intensidade no seio do agir humano, como uma aporia sem solução satisfatória.

As tarefas significativas que se esboçam ao nível da justiça humana vão preparando o recurso necessário a dois outros níveis, que constituem verdadeiros postulados para sustentar o nível humano imediato, com as suas tarefas e incumbências. Estes dois postulados situam-se a níveis diferentes, mas funcionam em linha de mútua convergência. É, por um lado, o postulado da justiça do rei e, por outro, o da justiça de Deus.

\section{A justiça do rei}

É evidente, por todo o antigo Oriente e pelas bases até agora expostas, que a matéria da justiça é um eminente problema político. As suas ligações com a função real são, assim, uma dimensão bem explícita em todas as suas culturas, tanto na Mesopotâmia como no Egipto ou em Israel ${ }^{33}$.

A acção do rei na prática e promoção da justiça situa-se a dois níveis imediatos e diferenciados. Um nível é o da sua governação; esta pode traduzir-se no cumprimento das suas obrigações para com os cidadãos e para com a sua sociedade. Outro nível é o da maneira como promove e dinamiza a justiça no meio da sociedade e entre os cidadãos que governa. Há, todavia, um nível menos imediato para a justiça do rei. É o de a sua actividade e intervenção poderem projectar justiça, mesmo para além das fronteiras que a sua acção imediata pode gerir. Este alcance é de mito e, mais uma vez, não tem limites. Volta a confirmar-se que a bitola da justiça pende mais para a dimensão do desmedido do que para as medidas bem padronizadas.

Qualquer dos dois primeiros níveis imediatos e práticos é exigível do ponto de vista da cidadania e oferece razões para que o rei possa 
ser aprovado ou criticado pelo seu modo de governar ${ }^{34}$. Este papel da realeza é considerado imprescindível por parte das sociedades do antigo Oriente ${ }^{35}$. Era por razões deste género que a realeza ali se apresentava como uma instituição de evidência comprovada, de eminência garantida e de exigência bem estabelecida.

Neste nível, o rei pode cumprir aquilo que se encontra já estabelecido e estipulado e pode também inventar, abrir caminhos e criar. O papel de criador cabe ao rei, em primeiro lugar e em sentido político evidente, antes mesmo de poder ser considerado também partilhado pelos seres humanos, enquanto imagens de Deus. Imitar Deus pelo exercício da governação e do poder é uma metáfora da acção política, antes de ser uma definição da função dos humanos no mundo. Pelo menos, na ordem das evidências será assim. A criação do homem à imagem de Deus ${ }^{36}$, em funções que implicam criatividade e governação, para além de ser uma definição antropológica universal, pode ter, também na Bíblia, uma leitura institucional complementar. Aquele papel humano universal de ordenar o mundo cabe, em primeiro lugar e superiormente ao rei, de uma forma reconhecida e oficial.

O outro nível de intervenção do rei na justiça, mais remoto mas não menos requisitado, consiste na expectativa que sobre ele recai, no sentido de contribuir para o bem estar geral dos seus súbditos, garantindo uma ordem que dificilmente se poderia garantir sem uma dose superior de sabedoria e até mesmo sem alguma participação na capacidade mágica de intervenção, que poderia ser apanágio dos deuses. A função de governar que é colocada nas suas mãos tem, deste modo, algo de divino. Desde cedo, os mesopotâmicos designavam este poder como a realeza divina ${ }^{37}$.

O prólogo e o epílogo do Código de Hamurabi são uma demonstração de que o poder desce do deus supremo, o sublime Anum, e recai em última escala, descendo a hierarquia de figuras divinas, nas mãos do rei Hamurabi. Este assume-o e desempenha-o nas funções de criador de justiça que é cuidar de todos, aos vários níveis que lhe compete assumir. Esta é a mensagem que, em síntese, se encontra contida no prólogo e se completa no epílogo do seu código ${ }^{38}$.

\section{A justiça de Deus}

Segundo o discurso que a Bíblia desenvolveu a propósito das intervenções divinas e suas modalidades, a lógica com que se desenvolve o tema da justiça de Deus é a de se posicionar como chave de cúpula, 
acima do rei e dos homens, com a finalidade de resguardar os mesmos objectivos de justiça.

O tema bíblico da justiça de Deus está, com muita frequência, ligado ao conceito de fidelidade e incide sobre as garantias com as quais se desenvolve o destino histórico e colectivo dos humanos. É naturalmente a propósito dos hebreus que ocorre mais amiúde esta narrativa. Mais do que gestão de contas muito estritas de justiça, aquilo de que se trata é da coerência lógica entre uma promessa feita por Deus e o cumprimento da mesma. O conceito de promessa é valorizado do lado de quem a recebe, concentrando-se a atenção mais propriamente no conteúdo concreto da promessa recebida. Esta percepção dos conteúdos de uma promessa apresenta-se naturalmente interligada com as expectativas essenciais. E estas incidem sobre as questões consideradas mais desejáveis. É por isso que a promessa de Deus é desejável e que a fidelidade à mesma se traduz em conteúdos de justiça. A promessa é a formulação de uma garantia relativamente àquilo que é desejável. E como o prometido passa a ser devido, o cumprimento das promessas por parte de Deus faz parte integrante do tema da sua fidelidade e justiça. Este é um conceito de honorabilidade divina que se espera e reiteradamente se celebra.

Esta justiça de Deus é uma resposta global às expectativas de confiança que os hebreus mantêm relativamente ao seu próprio futuro. Estas podem ser uma alínea da confiança geral com que os humanos se dispõem a enfrentar os caminhos do amanhã. É o postulado transcendental de confiança e a sensação fundamental de que o universo é lógico e corresponde de forma coerente às nossas expectativas.

Em formulação bíblica, o tema da justiça de Deus é uma versão da referida confiança global no funcionamento da vida e do universo, com as lógicas que se Ihes vão descobrindo. Essa confiança andava formulada nos já referenciados parâmetros da imputabilidade interpessoal.

Foi também por isto que nos pareceu pertinente começar este percurso dos universos da justiça pela consideração da experiência de justiça percebida como relação estruturante entre seres humanos. Daí que o discurso bíblico fale da justiça de Deus, quando relata os acontecimentos em que ela se realiza. Quando, por outro lado, relembra diante de Deus o filme desses acontecimentos de justiça, é sobretudo para frisar que os temas que ali ocorrem são matéria de hesed, que significa amor, ternura e compaixão, mas também de 'emet, ou seja, verdade e fidelidade.

Integrada desta maneira numa relação intensamente interpessoal, a justiça representa um sistema universal e englobante de confiança; é garantida com maior ou menor grau de evidência; e define-se segundo 
os parâmetros cálidos e coloridos que uma relação interpessoal comporta e matiza.

Constituindo um padrão para medir a realidade, a justiça é, afinal, um dos instrumentos de ponderação que mais naturalmente ocorre entre os humanos, se bem que seja também dos mais complexos e naturalmente misteriosos.

\section{Uma antropologia teológica fundada na justiça}

Da mesma maneira que a justiça formula e institui, em termos de ética interpessoal, os postulados de confiança que se referem ao mundo e à vida, assim também os institui quanto à avaliação axiológica do próprio comportamento ético. Assim vai contabilizando pela prática da justiça a dose de mérito ou de culpa que cada um acumula. Isto quer dizer que a qualidade, a dignidade e o mérito definem o estado bom ou mau e o valor maior ou menor de um ser humano. Isto mostra-nos uma visão da antropologia, operacional, criativa e ética, transformando a justiça no padrão mais eficaz para aferir da qualidade de cada ser humano.

Ocorre que para este apuramento se pode convocar o conceito de Deus como uma importante referência operativa. Formula-se então um sistema ético com envolvência transcendente: é uma antropologia teológica. No entanto, este aspecto teológico da semântica pode perfeitamente caber numa perspectivação metafísica. Digamos que se poderá definir como uma dimensão teológico-metafísica. Com efeito, em termos pré-clássicos, o teológico contém estatuto metafísico. Noutros contextos culturais, o teológico poderá eventualmente ser percebido como uma excrescência.

O conceito de justiça e a designação de alguém como justo servem, na tradição bíblica, para formular o mais alto valor humano reconhecido e devidamente consignado para uma pessoa.

Quando se diz que José assumiu um comportamento generoso e superior perante os sinais de uma gravidez desconhecida da sua prometida noiva, Maria; e quando se sublinha que ele se comportou de forma humana e generosa, porque era realmente "justo " ${ }^{39}$, não é certamente para declarar que ele estava a cumprir o que seria o seu dever mais estrito. O quilate máximo de humanidade que com o seu comportamento discreto assim se descreve pertence nuclearmente ao conceito de justiça, apesar de ser generoso e aparentemente impossível de ser exigido, porque transcende a lei. 
Quando, de modo bem mais generalizado, absoluto e definitivo, se resumem todos os caminhos de realização dos humanos, mostrando que, no final de todas as contas da vida, ao serem apresentados na instância definitiva do juízo final, eles são classificados como bons ou como maus. A fórmula da grande síntese consiste em dizer que os bons são justos e os maus são injustos ${ }^{40}$.

Sendo esta uma semântica subtil, pode ser útil desdobrá-la com outros adjectivos. Justapor, por exemplo, justo e santo ${ }^{41}$ ou ainda justo e bom ${ }^{42}$ é certamente um recurso retórico capaz de garantir mais conteúdo e maior evidência. É igualmente um recurso de segurança mínima garantir que a classificação de justo não seja feita por cada um em seu próprio proveito ${ }^{43}$. Cada um é o único responsável pela dose de justiça que consegue preencher, mas não lhe cabe declarar por si mesmo o nível que atingiu. $O$ estatuto de justo é uma declaração com estatuto forense; deve ocorrer por iniciativa de uma autoridade externa. Pois, ninguém é juiz em causa própria. $\mathrm{O}$ facto de $\mathrm{o}$ candidato egípcio à imortalidade fazer a sua auto-declaração de justiça proclamando a fórmula: «Sou puro! Sou puro! Sou puro! » ${ }^{44}$ tem certamente motivos de pertinência antropológica, mas não é o processo normal de declaração da justiça.

De facto, ser justo é ser inocente; é encontrar-se em estado humano natural. A injustiça é que é considerada um estado marginal, alheio ao padrão previsto para modelar o comportamento humano. Neste sentido, justiça soa como uma realização humana sadia e perfeita ${ }^{45}$; e, pelo contrário, injustiça é uma situação de desvio e de insucesso ou falha na realização do projecto humano. Compreende-se bem, por conseguinte, que a teorização antropológica do Novo Testamento se sirva do conceito de justiça (dikaiosyne) como uma maneira de formular o padrão da nova antropologia teológica. $O$ estado de justiça nas relações com Deus equivale àquilo que na linguagem escolástica e dogmática posterior, assente igualmente em fórmulas bíblicas, se costuma designar como estado de graça.

A literatura ligada à influência de Paulo é o espaço onde esta categoria se encontra mais amplamente utilizada. Paulo é, de facto, de entre os escritores canónicos do Novo Testamento, aquele que, de modo mais exímio, utiliza este conceito. Esta é uma das chaves principais do seu sistema de antropologia teológica; e o seu principal tratado sobre o assunto está na Carta aos Romanos ${ }^{46}$. Este pormenor conceptual contribui para fazer deste escrito um magno texto da literatura e da teologia cristãs ${ }^{47}$.

É interessante frisar, além do mais, que, apesar de a teologia de Paulo se afirmar com frequência em estado de ruptura radical com o pensamento judaico tradicional, esta teoria sobre o estado de realização 
reconhecida ao homem e designado como estado de justificação representa uma concepção que se encontra em perfeita continuidade com a tradição de pensamento do Antigo Testamento e se insere muito bem na concepção pré-clássica do mundo, visto como um estado ideal de ordem e eficácia, justiça e perfeição.

Contrariamente a outros movimentos da época helenística em que a realização humana e religiosa se orientava bastante para perspectivas mistéricas e esotéricas, o pensamento do Novo Testamento, claramente capitaneado pela intervenção de Paulo, insere-se na esteira do pensamento herdado da cultura bíblica e, mais amplamente, das restantes culturas do antigo Oriente. Com efeito, a definição do humano e o seu nível de realização processam-se ali, tomando como bitola e padrão o conceito de justiça.

Esta relação entre um estado de justiça que é objectivamente merecido pela prática e o direito a ter esse estado de justiça devidamente reconhecido e proclamado pela autoridade adequada leva provavelmente a que se verifique na Carta aos Romanos uma intensa dialéctica entre a justiça individual expressa pelo termo dikaios e o estado formal de justo, reconhecido e sancionado por Deus, expresso pelo termo dikaiosyne, já recheado de carga teológica. Este sancionamento marca a intervenção autorizada de Deus. É este matiz mais intenso de teologia que faz com que a expressão dikaiosyne (justiça) seja muito mais frequente na Carta aos Romanos do que o termo expressivo da objectividade ética, dikaios (justo).

A intima cumplicidade entre os dois matizes semânticos desta dialéctica torna algo difícil de aceitar uma tradução dos dois matizes demasiado desvinculados um do outro. É o que ocorre na proposta de traduzir a intervenção de Deus para a declaração de dikaiosyne como sendo um acto de colocar o homem em boas relações com a divindade ${ }^{48}$. É muito interessante verificar como foi incisivo o trabalho da comissão de revisão ${ }^{49}$ da proposta inicial de texto, entre a primeira tradução da Carta aos Romanos para a Sociedade Bíblica de Portugal $^{50}$ e a edição revista da mesma ${ }^{51}$. O texto de Rm 1,17 em ambas as versões pode ser aqui apresentado como exemplo da intensa busca hermenêutica entretanto ocorrida. Com efeito, na tradução inicial tinha-se optado pela seguinte versão:

"É esta Boa Nova que manifesta o plano que Deus tem de pôr toda a gente em harmonia com ele por meio da fé, desde o princípio até ao fim. A Escritura assim diz: "Aquele que, por meio da fé, está em boas relações com Deus, viverá"». 
$\mathrm{Na}$ edição posterior à revisão, ficou desta maneira:

"Nele (evangelho) se revela a justiça de Deus, por meio da fé. Como está escrito: "Aquele que é justo pela fé viverá"».

O ponto de divergência entre ambas as propostas de texto está na tradução do conceito de justiça. A justiça de Deus foi entendida como um plano e a justiça dos homens foi vista como um estado de harmonia com Deus. Tratava-se de ultrapassar a solução mais tradicional e literal de tradução, segundo o modelo ambicioso de hermenêutica que então presidia ao projecto $^{52}$. O retomar de uma tradução mais próxima do texto, mais literal, acabou por valorizar uma nova equivalência, entre fé e justiça. Esta nova equivalência pode ser sugestiva, mas não vamos investir nela agora.

No mar de questões que os textos de Paulo costumam suscitar, a hermenêutica costuma ser particularmente sensível ao confronto que nele se configura entre a lei e o espírito. Esse poderia ter sido o seu combate teórico e retórico principal. A sua missão exprime-se muito na contraposição desses dois conceitos como representando cada um deles uma fase da história, de configuração e sentidos divergentes: a antiga e a nova era da história da salvação, na sequência bíblica judaico-cristã, com grande dependência da hermenêutica da justiça. Entretanto, verificamos que a cisão hermenêutica que Paulo subtilmente opera é entre, por um lado, a lei, produtora de limite e de pecado, e, por outro lado, a justiça, geradora do excesso da generosidade. Então, justiça é graça e é salvação. Desta maneira, o cerne do pensamento judaico-cristão está a ser definido por Paulo, no âmago de uma antropologia transcendental que engloba toda a humanidade e abarca toda a dimensão do universo. Esta síntese pode representar igualmente o cerne do sentido da vida e do mundo segundo as concepções do Antigo Oriente pré-clássico.

Nada disto obsta a que a teologia que caracteriza o cristianismo, exposta principalmente nos textos de Paulo, nos pareça uma coisa extremamente original. Nada obsta, no entanto também, a que possamos verificar como ela acaba por incidir tão fielmente no cerne da teoria de uma visão da consistência essencial do universo, tanto humano como físico. Segundo esta maneira de ver, o universo está assente sobre o conceito de uma justiça, tão renovada e eficaz que pode até dispensar a força normativa que lhe emprestava o conceito de lei.

A um dado momento do combate de Paulo, poderia parecer que o conceito de justiça estaria destinado a ser por ele rejeitado, juntamente com a normatividade baseada na lei. Mas não. É, pelo contrário, sobre este conceito antiquíssimo de justiça, assente em intuições simples e 
imediatas da sensibilidade humanista e elaborado em semânticas múltiplas e profundas, que Paulo sistematiza a sua teoria da salvação e realização humana, baseada em dikaiosyne (justiça) e envolvida em kháris (graça).

A justiça representa aqui o mérito humano escrupulosamente medido e extravasando para uma generosidade que ultrapassa a bitola da lei. A graça significa que o facto de receber de Deus o reconhecimento e a ratificação (de equivalência forense) para esse mérito absoluto, a salvação representa igualmente um dom absoluto, uma oferta infinitamente graciosa. $\mathrm{O}$ inteiramente merecido é imensamente gratuito. Temos aqui um feixe de coordenadas dialécticas, servindo como leitura essencial de um humanismo teológico.

Por esta síntese, é assumido o essencial da concepção humanista do mundo oriental antigo, definindo um horizonte de grande univocidade, que vai desde a Suméria até ao Egipto e abrange desde o início da história ali conhecida até ao final do mundo pré-clássico. É este, afinal, o horizonte cultural da Bíblia, definido pelo conceito de justiça.

\section{Notas}

(1) Este texto teve, inicialmente, como destino figurar numa edição de homenagem ao colega José Ribeiro Ferreira, pela sua jubilação. Esse destino acabou por não se cumprir na forma prevista. Recolhido, entretanto, neste número de Cadmo, ele mantém a mesma intenção, reafirmada e sublinhada.

(2) Emanuel LÉVINAS, Autrement qu'être ou au-delà de l'essence, Dordrecht: Martinus Nijhoff, $1974,165$.

(3) José Augusto RAMOS, "Na margem oriental do classicismo», em José Eduardo Franco, Hermínio Rico (coord.): Padre Manuel Antunes (1918-1985): interfaces da cultura portuguesa e europeia, Lisboa: Campo das Letras, 2007, 94-98.

(4) José Augusto RAMOS, "Sobre o fim do mundo pré-clássico», em Biblos, vol. II (2 série), Coimbra, 2004, 44-49.

(5) Édouard LIPINSKI, "Justice», em Dictionnaire encyclopédique de la Bible, Turnhout: Brepols, $1987,707$.

(6) Cf. Luís Manuel de ARAÚJO, "Maet», em Luís Manuel de Araújo (dir.), Dicionário do Antigo Egipto, Lisboa: Caminho, 2001, 528-529.

(7) Jan ASSMANN, Ma'at: Gerechtigkeit und Unsterblichkeit im alten Ägypten, Munique: C. H. Bek, 1990, 15ss. O artigo citado de Luis Manuel de Araújo recolhe as ideias essenciais de J. Assmann, a partir de uma edição francesa, ali citada e anterior ao original alemão que aqui citamos. Deste último apresentámos uma recensão prolongada em Cadmo 2 (1992), Lisboa, 167-172.

(8) Jan ASSMANN, Ma'at, 122ss. 
(9) Samuel Noah KRAMER, Os Sumérios: sua história, cultura e carácter, Amadora: Bertrand, 1977, 142; Jean-Jacques GLASSNER, La Mésopotamie, Paris: Les Belles Lettres, 2002, 240-241.

(10) J. J. GLASSNER, La Mésopotamie, 241-243.

(11) Cf. G. R. DRIVER; John C. MILES, The Babylonian laws: vol I: Legal commentary, Oxford: Clarendon Press, 1968, 20-23; 37-39.

(12) Klaus $\mathrm{KOCH}$, «şdq, gemeischaftstreu/heilvoll sein», Ernst Jenni, Claus Westermann, Theologisches Handwörterbuch zum Alten Testament, II., München: Chr. Kaiser Verlag, 1984, 507-530.

${ }^{(13)} \mathrm{K} . \mathrm{KOCH}$, "şdq, gemeischaftstreu/heilvoll sein", 509 .

${ }^{(14)} \mathrm{K} . \mathrm{KOCH}$, "şdq, gemeischaftstreu/heilvoll sein", 510 .

(15) $\operatorname{Pr}$ 9,1-6.

(16) K. KOCH, "şdq, gemeischaftstreu/heilvoll sein», 511 .

(17) J. LUST, E. EYNIKEL, K. HAUSPIE, A greek-english lexicon of the Septuaginta, I, Stuttgart: Deutsche Bibelgesellschaft, 1992, 115-116.

(18) S. N. KRAMER, Os Sumérios, 205-212.

(19) Jacob KLEIN, “Enki and Ninmah», em William W. Hallo (ed.), The context of Scripture, I, Leiden: Brill, 1997, 516-518. Por seu lado, Elena CASSIN, Le semblable et le différent, Paris: Ed. La Découverte, 1987, 93-94, estende a consideração destas anomalias ao próprio tecido da sociedade.

(20) $\mathrm{Jb} 27,1-6$.

(21) Rib é o nome dado a uma disputa legal, a qual serve de esquema para a articulação literária de Job. Cf. Victor Morla ASENSIO, Libros sapienciales y otros escritos, Estella (Navarra): Verbo Divino, 1994, 153-155.

(22) Jb 38,1-42,6.

(23) Jb 42,7-17.

(24) Cf. José Nunes CARREIRA, Filosofia antes dos Gregos, Mem Martins: Publ. Europa-América, 1994, 202.

(25) Benjamin R. FOSTER: "The poem of the righteous sufferer", em Willam W. Hallo (ed.), The context of Scripture, I, Leiden: Brill, 1997, 486.

(26) É tentador pensar que o termo acádico nemequm que significa sabedoria assenta numa raiz que no semítico ocidental traduz sobretudo a profundidade.

(27) Os múltiplos dualismos gnósticos da época helenística, sejam de cariz mais religioso ou de molde mais filosófico, provavelmente, têm raízes ou apresentam, pelo menos, algum parentesco, com este pensamento dualista iraniano.

${ }^{(28)}$ Cf. GI 3,17-18; Rm 2,12ss.

(29) Cf. Is 58,6-10; Ez 18, 5-9.15-17; Jb 29, 12-17. Quando Job faz a revisão do seu próprio comportamento contabiliza a sua prática da justiça por esta bitola mais elevada da humanidade e da generosidade ( $\mathrm{Jb} 29,12-17)$.

(30) SI 112,9 .

(31) $1 \mathrm{Sm} 24,18$; Sir 3,$30 ; 7,10 ; 12,3 ; 29,12 ;$ Tb $4,7-11 ; 12,8$; Mt 6,1-3; 25, 37-39,46

(32) Mt 5,20. 
${ }^{(33)}$ Cf. José das Candeias SALES, A ideologia real acádica e egipcia, Lisboa: Ed. Estampa, 1997, 108-132;133-172.

(34) Pode ver-se, como simples exemplo, em Dt 17,14-20, as rápidas indicações sobre como legitimamente o rei deve conduzir a sua governação.

(35) O livro de Henri FRANKFORT, Reyes y Dioses, Madrid: Alianza Editorial, 1983, é tido como um clássico sobre o tratamento deste tema (163-233; 297-359).

(36) Gn 1,26-28.

${ }^{(37)}$ Este é o conceito determinante num texto sumério que recolhe S. N. KRAMER em Os Sumérios, integrado no sugestivo apêndice textual final.

${ }^{(38)}$ Cf. Emanuel BOUZON, O Código de Hammurabi, Petrópolis: Vozes, 1987, 39-45; 222-224.

(39) Mt 1,19.

(40) Mt 25, 37.46 .

(41) Mc 6,20; Act 3,17.

(42) Lc 23,50.

(43) LC 18,9.

(44) Raymond O. FAULKNER, The Ancient Egyptian Book of the Dead, Londres: British Museum, $1990,31$.

(45) $\mathrm{O}$ adjectivo tam caracteriza a integridade do comportamento humano e significa conjuntamente perfeito e sadio. É neste sentido quer ele se aplica a Job (Jb 1, 8; 2, 3 e noutros).

${ }^{(46)} \mathrm{Rm} 1,7$, etc. Este conceito justifica praticamente uma leitura contínua desta carta de Paulo, pois o conceito enforma quase todos os seus capítulos. Cf. Marc LODS, "Justification", em Dictionnaire encyclopédique de la Bible, Turnhout: Brepols, 1987, 709-711.

(47) Daí o facto de esta carta se encontrar frequentemente em lugar de grande confronto de ideias, ao longo da história do cristianismo. Haja em vista a maneira como serve de detonador de diferenças entre catolicismo e protestantismo, desde a época da Reforma. E já ai o tema da "justificação" era realmente o pomo da discórdia. O texto de maior polémica em vaivéns hermenêuticos tem sido do de Rm 1,7 ("o justo viverá pela sua fé/fidelidade", que constitui precisamente uma citação do Antigo Testamento ( $\mathrm{Hab} 2,4)$. Também o fundador da Escola Bíblica de Jerusalém, o P. Marie Joseph Lagrange, no tempo das lutas modernistas, se destacou por um famoso comentário.

${ }^{(48)}$ Cf. Johannes, P. LOUW, Eugene A. NIDA, Greek-Englischen Lexicon of the New Testament, based on semantic domains, Cape Town. 1993, I, 744; II, 64.

(49) Permitimo-nos tomar aqui este exemplo, porque nos tocou fazer parte de ambas as comissões de tradução.

(50) Bíblia Sagrada: tradução interconfessional, Lisboa: Sociedade Bíblica de Portugal, 1993.

(51) A Bíblia para todos, Lisboa: Sociedade Bíblica de Portugal, 2010.

(52) Sobre as intenções e modelos para esta tradução, pode ver-se José Augusto RAMOS, "Tradução interconfessional da Bíblia em português", em Cadmo, 3, Lisboa, 1993, 87-105; republicado em Revista Lusófona de Ciência das Religiões, Lisboa, 2009, 103-120. 